\title{
Is Testimonial Knowledge Second-Hand Knowledge?
}

September 22, 2015

\begin{abstract}
Fricker (2006a) has proposed that a hearer's knowledge that p acquired through trusting a speaker requires the speaker to know that $\mathrm{p}$, and that therefore testimonial knowledge through trust is necessarily second-hand knowledge. In this paper, I argue that Fricker's view is problematic for four reasons: firstly, Fricker's dismissal of a central challenge to the secondhandedness of testimonial knowledge is based on a significant misrepresentation of this challenge; secondly, on closer scrutiny an important distinction Fricker wants to draw is compromised by her account of trust; thirdly, Fricker's conception of trust is at odds with our natural understanding of this notion; fourthly, the reasons Fricker cites in support of her view are not sufficient to single out her view as the correct one, since rival views can also accommodate the relevant data.
\end{abstract}

\section{Introduction}

Must knowledge gained by a hearer solely through trusting a speaker's testimony be second-hand knowledge, i.e., knowledge that the speaker already has? The following principle underpins an affirmative answer:

\section{Second-Handedness of Testimonial Knowledge (SHTK):}

Necessarily, if (i) a hearer $\mathrm{H}$ forms the belief that p solely by trust- 
ing a speaker S's telling her that $\mathrm{p}$, and (ii) H's belief constitutes knowledge that $\mathrm{p}$, then $\mathrm{S}$ knows that $\mathrm{p}^{1}$

In 'Second-Hand Knowledge', Elizabeth Fricker articulates a rich and original account that seeks to explain why SHTK is true. In this paper I argue that her account is problematic in several ways. My primary interest is assessing the merits of Fricker's distinctive account of SHTK, rather than the merits of SHTK itself (although some of the remarks I make will bear negatively on the plausibility of SHTK).

This paper is structured as follows. I first describe Fricker's account in detail, highlighting the key elements of her view. In section 2 I show that Fricker's dismissal of a central challenge to SHTK by Lackey is based on a significant misrepresentation of this challenge. In the following two sections I critically examine Fricker's distinctive conception of trust: I argue that endorsing this conception jeopardizes a valuable distinction which any account of testimony should be able to draw, and which Fricker herself claims to have accommodated (section 3); and I show that this conception of trust is at odds with our natural understanding of the notion (section 4). I then argue in section 5 that Fricker's central argument in favor of SHTK, based on the alleged conventional role of tellings, does not adequately motivate SHTK: rather than providing distinctive evidence for SHTK, it also provides evidence for several rivals to SHTK.

\footnotetext{
${ }^{1}$ Several theorists endorse this principle. See, e.g., Ross (1975), Burge (1993, p. 486), McDowell (1994), Welbourne (1994), Reynolds (2002), Audi (1997, p. 410). For criticism of SHTK, see Lackey (1999) and (2008), Graham (2006), and Carter and Nickel (2014). I will be discussing Lackey's challenge in detail in what follows.
} 


\section{Fricker's Account of SHTK}

Fricker's account of SHTK can be broken down into six ingredient theses. In this section I provide a detailed exposition of each thesis.

\subsection{Thesis 1: In asserting $\mathrm{p}$ one purports to know $\mathrm{p}$}

Fricker's account of testimony gained through trust is offered as an answer to the question: when $\mathrm{S}$ tells $\mathrm{H}$ that $\mathrm{p}$ and $\mathrm{H}$ trusts $\mathrm{S}$, how does $\mathrm{S}$ gain license to believe that $\mathrm{p}$ ? Fricker is interested in what happens in paradigmatic, central and clear cases of testimony. Thus, Fricker sets aside the complications of cases where $\mathrm{H}$ is eavesdropping or reading words written in the past by $\mathrm{S}$, or where H doesn't trust S, or where p contains indexical elements, etc. Fricker's hope is that getting clear on the basic cases first will help us make sense of the complex ones later.

The datum to be explained is the following:

When a speaker $\mathrm{S}$ asserts that $\mathrm{p}$ to an audience or hearer $\mathrm{H}$ (by uttering a sentence of their shared language, apt for this speech act) she thereby vouches for the truth of $\mathrm{p}$ to $\mathrm{H}$. She presents $\mathrm{p}$ as being so, in an act whose import is that $\mathrm{H}$ can form belief that $\mathrm{p}$ on her say-so-H's eventual belief that $\mathrm{p}$ will be justified by reliance on S's word. (594)

How is this phenomenon to be explained? How can $\mathrm{H}$ gain a license to believe that $\mathrm{p}$ when $\mathrm{S}$ vouches for its truth in a paradigmatic, face-to-face testimonial encounter? Fricker begins to answer this question by examining the speech act of assertion. She writes:

In asserting that $\mathrm{p}$, the asserter offers her word that $\mathrm{p}$ to her intended audience $\mathrm{H}$. She licenses $\mathrm{H}$ to believe that $\mathrm{p}$ on her say-so. How so? What enables such a feat? It is the conventionally constituted force of her speech act that, in asserting $\mathrm{p}$, the speaker $\mathrm{S}$ purports to speak from knowledge. (594) 
Fricker is here endorsing the view that in asserting that $\mathrm{p}$ one purports to speak from knowledge that $\mathrm{p}$ and that this fact is determined by linguistic convention. On this train of thought, then, what enables $\mathrm{S}$ to vouch for the truth of $\mathrm{p}$ by asserting $\mathrm{p}$ is the fact that in asserting $\mathrm{p} \mathrm{S}$ purports to speak from knowledge. Fricker proceeds to describe in greater detail the role this feature of assertion plays in generating H's license to believe that $\mathrm{p}$ :

\begin{abstract}
In asserting that $\mathrm{p}, \mathrm{S}$ purports to speak from knowledge. But it is a priori and obvious that if $\mathrm{S}$ knows that $\mathrm{p}$, then $\mathrm{p}$. Thus once $\mathrm{H}$ gets into an epistemic position to know that $\mathrm{S}$ knows that $\mathrm{p}$, she thereby has a basis for knowledgeable belief that $\mathrm{p}$ herself. When $\mathrm{H}$ hears, with understanding of both its content and force, S's assertion that $\mathrm{p}$, then provided she has a basis to know that $\mathrm{S}$ is trustworthy, she comes to be in that position. Moreover, in knowing that $\mathrm{S}$ knows that $\mathrm{p}$, she thereby also knows that $\mathrm{S}$ possesses grounds or warrant strong enough for proper sureness that p. These facts are crucial to how H's belief that p, acquired through her trust in S's assertion, can be adequately grounded and so amount to knowledge. (595)
\end{abstract}

On Fricker's distinctive view, then, H's license to believe $\mathrm{p}$ is grounded in the joint work of several facts: firstly, the fact that $\mathrm{S}$ purports to speak from knowledge; secondly, the fact that $\mathrm{H}$ trusts $\mathrm{S}$, and so can come to believe that what $\mathrm{S}$, in asserting that $\mathrm{p}$, purports herself as doing (i.e. as knowing $\mathrm{p}$ ) is precisely what she does (i.e. know that p); thirdly, the fact that knowledge is factive, and consequently that if $\mathrm{S}$ knows that $\mathrm{p}$, then $\mathrm{p}$ is true.

\title{
2.2 Thesis 2: Trusting $\mathrm{S}$ is constituted by the belief that $\mathrm{S}$ is trustworthy
}

After proposing this picture, Fricker narrows the focus to a subset of assertions: trusted tellings. The motivation for this is Fricker's aforementioned wish to concentrate on the clearest, paradigmatic instances of testimony, screening off any potential complications. She thus homes in on a sub-class 
of assertions she calls tellings. All tellings are assertions, but not all assertions are tellings: the distinguishing feature is that tellings apparently ${ }^{2}$ aim to let a hearer know that $\mathrm{p}$, where - distinctively-the hearer is believed by the speaker to be ignorant or possibly ignorant of $p .^{3}$. This feature is not essential to assertions: a student may assert in an exam that the Congress of Vienna ended in 1815 without aiming to inform her history professor of this fact. The speech act she performs is thus an assertion but not a telling.

Fricker further narrows the focus on a sub-class of tellings: tellings that are trusted by the hearer. The notion of trust plays a distinctive and fundamental role in Fricker's account. Fricker explains what it means to trust a telling:

to trust a particular telling is to trust the teller, regarding that particular utterance. [The hearer H's] belief about $\mathrm{S}$ which constitutes her trust, antecedent to $[\mathrm{S}$ 's] utterance, is something like this: $\mathrm{S}$ is such that not easily would she assert that $\mathrm{p}$, vouch for the truth of $\mathrm{p}$, unless she knew that $\mathrm{p}$. Call this dispositional property of $\mathrm{S}$ her trustworthiness with regard to $p$. (600)

Fricker here maintains that H's trusting S's telling that $\mathrm{p}$ is constituted by H's belief that $\mathrm{S}$ is trustworthy, i.e. her belief that $\mathrm{S}$ would not easily assert that $\mathrm{p}$ unless $\mathrm{p}$. There are two things to note: firstly, according to Fricker, we should think of trust as localized to individual tellings: she speaks (here and throughout her argument) of trusting a particular telling, and not a speaker generally. Secondly, Fricker moves freely between the locutions 'trusting S's

\footnotetext{
${ }^{2}$ Only apparently, because $\mathrm{S}$ may maliciously tell $\mathrm{H}$ that $\mathrm{p}$ even while knowing $\mathrm{p}$ to be false, and so without actually aiming to inform $\mathrm{H}$ of the truth of p. On Fricker's account of tellings, which in this respect dovetails with a common usage of 'telling', tellings can be false.

${ }^{3}$ This account as stated in Fricker (2006a) seems to differ from Hinchman's, who thinks that whether $\mathrm{S}$ tells $\mathrm{H}$ that $\mathrm{p}$ depends on $H^{\prime}$ 's recognition that $\mathrm{S}$ intends $\mathrm{H}$ to gain an entitlement to believe p, rather than merely on S's intention that this happen (see Hinchman (2005)). However, in other work Fricker insists that a successful telling requires H's recognition, thus bringing her account closer to Hinchman's (Fricker (2002, p. 376)
} 
telling that p' and 'trusting the teller with regard to the utterance that p'. I will also use them equivalently, although to ease exposition I will omit the clause 'with regard to the utterance that p' when talking about trusting a speaker, with context providing the proposition to which trust is relative. ${ }^{4}$

This conception of trust, on which trusting a speaker is constituted by believing that the speaker wouldn't easily say that $\mathrm{p}$ without knowing $\mathrm{p}$, allows it to play its crucial role in Fricker's account of the hearer's acquisition of testimonial knowledge:

\begin{abstract}
S's trustworthiness with regard to $\mathrm{p}$, conjoined with the fact that she asserted $\mathrm{p}$, is strong evidence that she knows that $\mathrm{p}$. This is how a hearer can come to know that $\mathrm{p}$, and that the teller $\mathrm{S}$ knows that $\mathrm{p}$, in consequence of knowing that $\mathrm{S}$ told her that $\mathrm{p}$, and that $\mathrm{S}$ is trustworthy with regard to $\mathrm{p}$. Her knowledge of the last two facts grounds her belief in the second, which in turn grounds her belief in the first. (600)
\end{abstract}

Here Fricker describes the argument (which I will call 'The Grounding Argument') that sustains the hearer's knowledge of what the speaker told her. This can be formulated as follows. ${ }^{5}$

\title{
The Grounding Argument
}

1. S told me that $\mathrm{p}$ [perception]

2. S would not easily tell me that $\mathrm{p}$ unless $\mathrm{S}$ knew that $\mathrm{p}$ (Trustworthiness)

\section{3. $\mathrm{S}$ knows that $\mathrm{p}[1,2]$}

\footnotetext{
${ }^{4}$ Although it is controversial whether the two locutions should be interchangeable, I will assume them to be so in the present context of criticizing Fricker's view.

${ }^{5}$ Fricker is rightly adamant that this argument only spells out the epistemic grounding relations between beliefs that can be attributed to the hearer, and does not necessarily illustrate the actual inferential process a hearer goes through in order to acquire belief that p. Consequently, the hearer's knowledge of p may be based on the grounding argument even though the hearer does not consciously perform the inference from the argument's premises to its conclusion.
} 
4. If $\mathrm{S}$ knows that $\mathrm{p}$, then $\mathrm{p}$ (Factivity) [a priori]

5. $\mathrm{p}[3,4]$

\subsection{Thesis 3: $S$ knows that $p$ is a crucial premise in H's justification for $p$}

An important consequence of this account is that the speaker's knowledge that p, captured in premise 3 of The Grounding Argument, plays an essential role in allowing the hearer to come to know p via the speaker's testimony, as Fricker stresses:

when the hearer's belief in what she is told is thus based in trust of the teller, she takes him to be speaking from knowledge. That the teller knows what he asserted is a key premiss in her justifying grounds for her belief in what she was told. This is the distinctive mechanism involved in the spreading of knowledge through trust in telling, and in testimony more broadly (601)

and

[the hearer's] gaining knowledge, when she does, depends on the speaker's knowing what he asserts [...] This is a key premiss in H's justifying grounds for her belief. If S did not know, then H's justification for her belief would contain a false premise, and so that belief would not be knowledge - even if $\mathrm{S}$ had in fact spoken truly, though not from knowledge. (602-3)

\subsection{Thesis 4: Trust is empirically grounded}

Two further important points about trust are in order. The first is that Fricker believes that there must be grounds for H's trusting S, i.e., grounds for H's belief that $\mathrm{S}$ would not easily assert $\mathrm{p}$ unless $\mathrm{S}$ knew $\mathrm{p}$, and that these must be empirical:

I think this belief in the teller's trustworthiness needs to be empirically grounded. There is no general epistemic entitlement to trust any teller, just so long as one lacks evidence of her untrustworthiness. (599) 
The groundedness of trust stems from Fricker's antecedent commitment to reductionism about central cases of testimony, ${ }^{6}$ a position deemed incompatible with a default entitlement to accept testimony in the absence of countervailing evidence, which anti-reductionism posits.

\title{
2.5 Thesis 5: An important distinction
}

The second point to note about trust is that Fricker endorses a commonplace distinction between knowledge acquired through trusting a speaker's telling (this is the category Fricker is interested in) and knowledge acquired merely in virtue of being the audience to a (non-trusted) speaker's telling. ${ }^{7}$ Fricker illustrates the point with an example:

\begin{abstract}
Suppose I somehow come to know of the bizarre contingent correlation that when and only when Pinocchio utters a truth, his nose becomes visibly shorter. When Pinocchio asserts that $\mathrm{p}$, and his nose shrinks, I have reason to believe that $\mathrm{p}$. But this is not via my belief that he is sincere, and speaks from knowledge. My basis for my belief does not refer back to Pinocchio's presumed knowledge of, or warrant for, what he asserts. It is not a case of knowledge gained through trust in testimony, and unlike this, it is not knowledge gained at second-hand. We do not regard or treat others as mere natural signs of what they assert, nor merely as measuring instruments, when we believe what they tell us through our trust in them. The fact that our belief in their trustworthiness is, or at least should be, empirically based, in no way undermines this point. (602)
\end{abstract}

Fricker's plausible point here is that knowledge obtained via trusting a speaker's telling should be demarcated from knowledge obtained merely through treating a speaker as a natural sign of what they assert. It would be problematic

\footnotetext{
${ }^{6}$ See Fricker (1987), (1994), (1995), (2002), (2004), (2006b) for details of her reductionist view. Note that Fricker thinks that the reductionist picture only applies to epistemically mature humans. By contrast, testimonial knowledge possessed by those who have yet to reach epistemic maturity (e.g. small children) cannot be reduced to non-testimonial justification. (Fricker (1995)). Following Fricker (2006a), I will only discuss testimonial transactions involving hearers who are epistemically mature.

${ }^{7}$ See Lackey (2008, p. 42) and Audi (1997, p. 420) for further endorsements of this distinction.
} 
if in this case, where Pinocchio is clearly treated merely as a natural sign of p, the hearer trusted Pinocchio in Fricker's sense of trust. Importantly, however, the subject does not trust Pinocchio because the subject doesn't believe that Pinocchio is trustworthy, i.e. that Pinocchio wouldn't easily assert that p unless Pinocchio knew that p. The lack of this belief is compatible with the hearer's taking Pinocchio's assertion and the shrinking of his nose as a reason to believe that $\mathrm{p}$.

\subsection{Thesis 6: Lackey's challenge fails}

Fricker is aware of a potential challenge to her view. Lackey (1999) and (2008) has proposed cases in which a hearer allegedly gains knowledge that $\mathrm{p}$ from a speaker who doesn't know that p. These cases are in tension with SHTK, which requires instead that if a hearer gains testimonial knowledge that $p$, then the speaker must know that p. Lackey's central case involves Stella, a creationist teacher who understands her professional responsibility not to allow her beliefs to interfere with the delivery of the curriculum. She therefore teaches her pupils evolutionary theory to the best of her abilities, despite not believing this theory to be true. Lackey argues that the pupils can come to know the facts of evolutionary theory and its consequences, despite Stella's lacking belief in, hence knowledge of, the facts of evolutionary theory which she teaches. If this kind of case is possible, is Fricker's account undermined? In a footnote, Fricker responds to this worry:

Lackey argues that one can acquire knowledge that $\mathrm{p}$ from testimony that $\mathrm{p}$, even though the testifier does not know that p. I agree with her. My Pinocchio case is precisely such a case. Where I disagree with Lackey, is on how testimony as an epistemic source is best theorized. I have described the case where the hearer forms belief in what she is told due to her trust in the teller, taking her speech act at face value, as an expression of knowledge. The result that a recipient of testimony can come to know what she is told 
only if the teller speaks from knowledge holds only for this relatively narrow category. I believe this is the distinctive core mechanism we need to identify, to understand testimony as a socio-linguistic means of spreading knowledge. Lackey instead suggests that, to understand how knowledge can be acquired from others' testimony, we should focus on the question: who are the reliable testifiers? And she introduces several cases of reliable testifiers that $\mathrm{p}$ who do not know that p. While I agree that knowledge may be acquired in some of these cases, it is not by means of the core mechanism of trust. Focussing instead on Lackey's question neglects the nature of the speech act of telling, and thus does not enable us to understand how testimony works to spread knowledge when it is functioning properly, in accordance with the nature of the speech act. (603-4)

Fricker's objection is that Lackey has wrongly focused on the speaker's reliability rather than on the hearer's trusting the speaker. According to Fricker, SHTK holds in the relatively narrow (yet central) category of testimonial knowledge acquired through 'the core mechanism' of trust, although SHTK does not hold in cases like the Pinocchio example where testimonial knowledge is not acquired through trust.

\subsection{Taking Stock}

Here ends my sketch of Fricker's rich account. It's time to take stock and recap its key theses.

Thesis 1: In asserting that $\mathrm{p}, \mathrm{S}$ purports to know that $\mathrm{p}$.

Thesis 2: H's trusting S's telling that $\mathrm{p}$ is constituted by H's belief that $\mathrm{S}$ is trustworthy with respect to p, i.e., by H's belief that $\mathrm{S}$ would not easily have asserted $\mathrm{p}$ unless $\mathrm{S}$ knew that $\mathrm{p}$.

Thesis 3: $S$ knows that $p$ is a crucial premise in H's justification for believing $\mathrm{p}$ by trusting S's telling.

Thesis 4: Trust must be supported by empirical grounds. 
Thesis 5: There is an important distinction between knowing through trusting a speaker's telling and knowing merely through being the audience of a telling.

Thesis 6: Existing challenges of testimonial knowledge that p gained from speakers who don't know that p (e.g. Lackey's Creationist Teacher) don't fall under the remit of knowledge gained through trust and so don't falsify SHTK.

In the rest of the paper I will move four objections to Fricker's account. My first objection is that Fricker's dismissal of Lackey's central putative counterexample to SHTK (Thesis 6) is based on a significant misrepresentation of this case. My second objection is that one cannot preserve the natural distinction between acquiring knowledge by trusting a speaker's telling and acquiring knowledge through being an audience of a telling (Thesis 5) while endorsing Fricker's account of trust (Thesis 2) and insisting that trust must be grounded empirically (Thesis 4). My third objection is that Fricker's account of trusting a telling (Thesis 2) is at odds with the natural understanding of trust that should be relevant to epistemologists of testimony. My fourth objection is that Fricker provides insufficient motivation both for the view that in asserting that $\mathrm{p}$ one purports to know that $\mathrm{p}$ (Thesis 1) and for the view that S's knowledge plays an essential role in H's grounds for believing S's testimony (Thesis 3). These objections jointly warrant rejecting Fricker's view.

\section{Fricker on Lackey's Challenge}

Fricker takes herself to have provided an original and satisfactory explanation of SHTK. However, anyone who endorses SHTK must have something to say 
against the alleged counterexamples to this principle of the kind initially proposed by Lackey $(1999,2008) .{ }^{8}$ As we have seen, Fricker agrees with Lackey that testimonial knowledge that $\mathrm{p}$ can be acquired from a speaker who doesn't know that $\mathrm{p}$, but that for the narrower category of testimonial belief gained by trust, the speaker must know that $\mathrm{p}$ if the hearer knows that p:

I have described the case where the hearer forms belief in what she is told due to her trust in the teller, taking her speech act at face value, as an expression of knowledge. The result that a recipient of testimony can come to know what she is told only if the teller speaks from knowledge holds only for this relatively narrow category [i.e. knowledge gained through trust] (603)

But it's not hard to see that Fricker's response to Lackey attacks a straw man, and brief reflection on the kind of case Lackey proposes reveals that Fricker's contention is illegitimate. Recall that in Lackey's central case, Stella is a creationist teacher who teaches her pupils evolutionary theory without herself believing it. Several objections could be and have been raised to this example (though, to my mind, none are compelling). ${ }^{9}$ Yet what seems undeniable is that the pupils trust what Stella says: each pupil, in Fricker's words, 'forms belief in what she is told due to her trust in the teller, taking her speech act at face value, as an expression of knowledge' in the way pupils typically do with their teachers. It is important to note that this holds true

\footnotetext{
${ }^{8}$ Some background: Lackey (1999) proposed several cases in which allegedly a hearer acquires testimonial knowledge that $\mathrm{p}$ from a speaker who doesn't know that $\mathrm{p}$. In her (2008), Lackey dropped all cases except for Creationist Teacher (probably because they are weaker cases) and added a new one called Consistent Liar. I will only discuss Creationist Teacher as it is Lackey's central case and the one most discussed in the literature. I will not discuss Consistent Liar, since it would be unfair to object to Fricker for not accommodating a case that was published after her (2006a) was. Nor will I discuss Peter Graham's case of testimonial knowledge from non-knowledge Graham (2006), as it is simply a version of Creationist Teacher tweaked to avoid the objection that the textbook author, not the teacher, is the source of testimony - an objection that is not relevant to my discussion.

${ }^{9}$ See, e.g. Audi (2006) and (2007). For discussion of this objection and of other potential objections to the case, see Lackey (1999), and (2008, p. 77-79) and Graham (2006).
} 
even on Fricker's idiosyncratic account of trust, understood as the belief in the counterfactual: Stella would not easily assert that $p$ unless she knew that $p$. In the absence of information to the contrary, it is exceedingly plausible to think that the pupils in the classroom hold this belief. ${ }^{10}$ Therefore, Fricker's contention that the pupils' acquisition of knowledge of evolutionary theory through Stella's tellings does not involve the core mechanism of trust seems hard to accept. In making this claim, Fricker significantly misrepresents the nature of the challenge to SHTK.

As further evidence for the view that the pupils obtain their knowledge by trusting Stella's testimony, consider the stark difference to the contrast case where the hearer acquires knowledge, but not through trusting the speaker's testimony. In the Pinocchio case which Fricker provides as an example of this kind, the hearer comes to know p when Pinocchio asserts $\mathrm{p}$ and observes Pinocchio's nose shrink, but Pinocchio's telling is not trusted (i.e. the hearer does not believe Pinocchio would not say that $p$ unless he knew that $p$ ); rather, he is being used as a natural sign of the truth of p. It is reasonable to think that Pinocchio's assertion in isolation should not rationally move a hearer to believe that $\mathrm{p}$ : only this assertion in tandem with the observation of his nose shrinking would suffice to overcome the hearer's initial restraint from believing p upon hearing Pinocchio's assertion.

This is wholly unlike the situation of Stella and her pupils. It is implausible that the pupils are using Stella only as a mere natural sign of the truth of evolutionary theory and its claims: it's not the case that pupils should

\footnotetext{
${ }^{10}$ One part of Lackey's multi-pronged response to Fricker (in Lackey (2008, p. 98-102)) is that in an intuitive sense, the pupils trust Stella. But Lackey misses the dialectically stronger point I've made here, that even by Fricker's own idiosyncratic conception of trust, the pupils trust Stella. So Fricker's own view - and not just arguments independent of her views - stands in tension with her objection that the knowledge acquired by the pupils is not gained through trust.
} 
rationally refrain from believing the facts Stella about evolutionary theory which she asserts until some further sign of Stella's truthfulness on this occasion is forthcoming. That the cases of Stella and Pinocchio look so different puts severe pressure on Fricker's claim that pupils' knowledge is not gained by trusting Stella's tellings. ${ }^{11}$

In sum, Fricker's dismissal of Lackey's case is overly quick: this case exhibits precisely the features we (and Fricker) would expect of a case where knowledge is gained by the hearers trusting the speaker's telling.

\section{Pinocchio and Burattino}

A second problem for Fricker's view is that two of its elements stand in tension: on the one hand, her conception of trust and, on the other, the distinction Fricker draws between coming to know through trusting the speaker's telling and coming to know merely through being an audience to a speaker's telling - a distinction which Fricker wishes, quite rightly, to preserve. This tension is exacerbated by Fricker's view that the justification $\mathrm{H}$ has for believing that $\mathrm{S}$ is trustworthy-i.e., that $\mathrm{S}$ would not easily tell $\mathrm{H}$ that $\mathrm{p}$ unless S knew p-must be empirical.

To explain this tension, let's return briefly to the Pinocchio example that

\footnotetext{
${ }^{11}$ Fricker might try to reply by conceding that the pupils trust Stella, that they gain knowledge of p, yet maintain that their knowledge is not acquired by trust. But this looks mysterious. If one is already committed to the view that trust (as conceived by Fricker) accounts for testimonial knowledge, what else could account for the pupils' knowledge in this case, where trust is patently present? If this line of response is viable, Fricker bears the onus of providing a satisfactory account of when, in the presence of trust, knowledge is acquired by this trust and when it isn't. On pains of begging the question this account cannot simply appeal to whether the speaker knows or doesn't. The viability of this reply on Fricker's behalf also depends on her providing an adequate account of how to distinguish cases where knowledge is gained in the presence of trust but not by trust, and when it's gained in the absence of trust, i.e. merely by being an audience to testimony. I am grateful to an anonymous referee for raising this point.
} 
Fricker uses to illustrate this distinction. You know antecedently that Pinocchio's nose shrinks just in case his telling is true; on one particular testimonial occasion, Pinocchio asserts p and you see his nose shrink, so you thereby come to believe that p. This, Fricker correctly claims, should not count as knowledge through trusting Pinocchio's telling; it is instead merely an instance of knowledge acquired by way of being an audience to Pinocchio's telling. Pinocchio is not trusted - he is being treated as a 'mere natural sign' for the truth of his utterance.

A simple variation on the example, however, spells trouble for Fricker's view. ${ }^{12}$ Imagine you discover the following bizarre contingent fact about Pinocchio's brother, Burattino: Burattino's nose shrinks just in case he knows the content of the telling he asserts. Suppose that in telling you that $\mathrm{q}$, Burattino's nose shrinks, and you thereby come to believe that he knows that $\mathrm{q}$, and that therefore $\mathrm{q}$ is true. Just as your knowledge that $\mathrm{p}$ was not based on trust when you heard Pinocchio say p and saw his nose shrink, so your belief that q formed on the basis of Burattino's telling you that $q$ and seeing his nose shrink should not count as being based on trust-after all, you are in the latter case also treating Burattino 'as a mere natural sign' of what he asserts. The problem, however, is that because you are aware of the bizarre correlation between Burattino's knowledge and his nose shrinking you do believe the counterfactual: Burattino would not easily have asserted $q$ unless he knew q, which means, on Fricker's account, that you trust Burattino with respect to q, since it is precisely your belief in this counterfactual that,

\footnotetext{
${ }^{12}$ Thanks to Elia Zardini for his help in developing this objection.
} 
Fricker thinks, constitutes your trusting his telling on this occasion. ${ }^{1314}$

Fricker's account, then, mandates contradictory verdicts about this case: on the one hand, you don't trust Burattino's telling that q because (just like with Pinocchio), intuitively, you treat him as a mere natural sign of the truth he asserts; on the other, you trust Burattino's telling that q because you hold the belief in the counterfactual that on Fricker's view constitutes his trustworthiness with respect to q. The case of Burattino shows that Fricker's understanding of trust as belief in the relevant counterfactual makes her account unable to preserve the natural distinction between knowing through trusting S's telling and knowing merely through being an audience to S's

\footnotetext{
${ }^{13}$ One might resist the thought that you believe this counterfactual on the grounds that it is not entailed by your belief in the biconditional Burattino knows that $p$ just in case $p$. While it's true that there is no relation of entailment between the biconditional and the counterfactual, this is far too strong a requirement. It is sufficient that in this case your evidence provides adequate (though perhaps non-entailing) justification to believe the counterfactual. We could also stipulate, without loss of effectiveness, that you have observed the correlation between Burattino's nose shrinking and his knowledge many times in the past. This would serve as an adequate basis for believing the counterfactual. Note that even with the aid of this observational evidence you are still treating Burattino as an instrument on this occasion, since your acceptance of his testimony depends on the fact that his nose shrinks. In other words, adding the evidence from past observations of the bizarre correlation is compatible with the fact that you wouldn't believe him outright without the additional evidence of his nose shrinking. Thanks to Tim Button and Branden Fitelson for discussion of this point.

${ }^{14}$ Although Fricker does not discuss this in detail, there is some textual evidence suggesting that she thinks of belief in the counterfactual that constitutes trust as prior to the actual utterance, when she writes 'But her [H's] belief about $\mathrm{S}$ which constitutes her trust, antecedent to her utterance, is something like this: $\mathrm{S}$ is such that not easily would she assert that p, vouch for the truth of p, unless she knew p.' (600, my emphasis). I'm not sure if this is always a good way to think about this belief; after all, one would want to allow that a belief concerning the content of someone's utterance might be formed $a f$ ter the speaker has uttered that content, since the speakers' trustworthiness (as Fricker acknowledges when she localises trust to specific tellings) can vary depending on the topic they speak of and on what they say. Be that as it may, we can easily adjust the Burattino example to accommodate the view that trust must be antecedent to the utterance. We just need to assume that you are aware of the following contingent fact about Burattino: his nose shrinks just in case the content he is about to assert is something he knows, and you have seen his nose shrink just before he asserted p. Thanks to an anonymous referee for raising this issue.
} 
telling. ${ }^{15}$

Fricker could try to block this objection by arguing that, in evaluating whether you trust Burattino's telling that q, your background knowledge about Burattino's nose and what it indicates about his knowledge should be screened off, so that the question of whether you trust him on this occasion is reduced to the question of whether you would believe that Burattino is trustworthy regardless of your seeing his nose shrink and knowing what this means. Since, presumably, without this background knowledge you would lack adequate grounds for believing the relevant counterfactual, you would not count as trusting Burattino on this occasion.

The difficulty for this response, however, is that it is philosophically unmotivated. Without a principled distinction between the kind of knowledge that should be screened off from the kind of knowledge that is allowed to count in determining whether the hearer believes the relevant trustworthinesscounterfactual, this response is ad hoc: we would be left wondering why in determining whether you believe that Burattino is trustworthy, your knowledge about Burattino's nose should be screened off, whereas in determining whether you believe a normal speaker to be trustworthy, your knowledgesay - of their past reliability on the topic they speak of should be allowed to count. At the very least, Fricker would need to say more about what

\footnotetext{
${ }^{15}$ One might object that upon hearing Burattino and observing his nose shrink you might not form belief in the trust-constituting counterfactual, but rather form belief in a different counterfactual, such as Burattino's nose would not have shrunk unless he knew that p. But this objection is not compelling, because belief in the trust-constituting counterfactual need not be occurrent - it must merely be something the hearer would assent to, if she considered it. And clearly, the hearer who hears Burattino's assertion, sees his nose shrink and knows of the bizarre correlation between the latter and Burattino's knowledge of what he asserts would assent to the trust-constituting counterfactual. Fricker's insistence that the Grounding Argument gives an epistemic, not a psychological, account of how testimonial belief is justified dovetails with this point - the hearer need not explicitly consider any of the premises of that argument, including the content of the trust-constituting belief which is a premise in that argument. But, importantly, she would assent to this content if she considered it.
} 
distinguishes the kind of empirical justification that can ground belief in Burattino's trustworthiness from the kind of empirical justification - of which the considerations about his nose are an instance - that involve using Burattino merely as a 'natural sign' of the truth of his assertions.

Two obvious ways around this problem would be to maintain either (a) that the basis for one's trust in a speaker is a priori, i.e., that trusting a speaker is epistemically legitimate only in virtue of the fact that hearers enjoy a defeasible a priori justification to believe what speakers say; ${ }^{16}$ or (b) that one's trust does not require any basis, since trusting is something we are entitled to do by default, without positive evidence. Either option would avoid the objection precisely because your knowledge of the bizarre contingent correlation between Burattino's nose shrinking and his knowing what he asserts - which grounds your belief in the counterfactual: Burattino would not easily tell me that q unless he knew that $q$-is the kind of fact that seems only knowable a posteriori. On proposal (a) this fact is precluded from being relevant in virtue of its a posteriori knowability. On proposal (b) it would be precluded from being relevant because no supporting reasons for trust are required.

Unfortunately for Fricker's position, her reductionist commitments force her to maintain that trust must be grounded, and empirically so. These commitments close off both ways out of the problem. It is then hard to accept Fricker's (unargued-for) contention-about the point that knowing via trust is distinct from knowing via being an audience of the speaker's telling - that '[t]he fact that our belief in [speakers'] trustworthiness is, or at least should be, empirically based, in no way undermines this point'. (602)

\footnotetext{
${ }^{16}$ See, for instance, Burge (1993) for a way to flesh out this view and Malmgren (2006) and (2014) for criticisms of this view.
} 


\section{$5 \quad$ Trust As Belief?}

A further problem for Fricker's distinctive account of trust is that it is at odds with the correct understanding of this notion. It is not surprising in this connection that the dominant view in the literature is that trust cannot be captured, as Fricker attempts to do, simply in doxastic terms (for example, in terms of one's belief that the trustee is trustworthy or in terms of the belief that the trustee will do what is expected by the truster).

Richard Holton (1994, p. 63) draws on the drama class 'trust exercise' of letting oneself fall in order to be caught by another member of the group:

Does my decision to trust others [to catch me] entail that I believe that they will catch me? If it does, does this in turn mean that when I decide to trust them, I also decide to believe that they will catch me? I think not. In order to trust I do not need to believe.[my emphasis]

Karen Jones (1996, p. 4) defends an account of trust according to which

trust is an attitude of optimism that the goodwill and competence of another will extend to cover the domain of our interaction with her, together with the expectation that the one trusted will be directly and favorably moved by the thought that we are counting on her. The attitude of optimism is to be cashed out not primarily in terms of beliefs about the other's trustworthiness, but rather - in accordance with certain contemporary accounts of the emotionsin terms of a distinctive, and effectively loaded, way of seeing the one trusted. [my emphasis]

In talking about the kind of trust he believes to be relevant in testimonial exchanges, which he calls affective trust, Paul Faulkner (2007, p. 885) writes:

it is an essential feature of affective trust that it need not be evidence based. We can choose to affectively trust in a way that we cannot choose to believe, or equivalently predict.

And while admitting that there is a sense of trust that involves making 'strategic judgements about others based on the weighing of evidence for and against their reliability', Victoria McGeer (2008, p. 240) maintains that 
theorists generally agree that there is an important phenomenon of substantial trust, as we might call it, that neglects or abjures such strategic judgements. Specifically, substantial trust may be characterized by two related features: (1) it involves making or maintaining judgements about others, or about what our behaviour should be towards them, that go beyond what the evidence supports; and (2) it renounces the very process of weighing whatever evidence there is in a cool, disengaged, and purportedly objective way

and devotes her project to explaining how this kind of non-evidential trust can be rational.

These passages indicate that accounts of trust that do not understand this notion wholly in evidential, and hence doxastic, terms are widespread. ${ }^{17}$ The reason they are widespread is that a doxastic account of trust fails to align with a commonsense and intuitive understanding of trust, according to which trust and belief can and do come apart. The difficulty here for Fricker is twofold: on the one hand, trust is sometimes constrained by pragmatic considerations that do not necessarily constrain belief, so one can be forced to trust despite the evidence; on the other hand, trust is free from evidential considerations that typically bind belief, so one can choose to trust despite the evidence. I'll illustrate both ways in which trust and belief can come apart, both generally and in the particular context of testimony.

Suppose that by some cruel twist of fate, I find myself in a life-threatening situation while mountaineering, and, of all people, it is my arch-enemy who is in a position to help. He lowers a rope and offers to pull me to safety. I would not want to, but in these circumstances I am forced to trust him

\footnotetext{
${ }^{17}$ More evidence for this view: in an introductory list of the distinctive features of trust, Katherine Hawley (2014) includes the fact that '[p] ractical reasons to trust can outstrip the evidence', which suggests that trust is distinct from belief. Even Annette Baier, who in her groundbreaking (1986) claimed that one cannot decide to trust, later conceded that trusting is something we may decide to do (Baier (1992, p. 123)). On the reasonable assumption that one cannot believe at will, this puts pressure on doxastic accounts of trust. For one dissenting voice, however, see Pamela Hieronymi's doxastic account of trust that seeks to explain away these non-doxastic phenomena (Hieronymi (2008)).
} 
to pull me to safety, and this is what I do when I take the rope and place my life in his hands, even though I lack the belief that he will pull me to safety - indeed, even though I may believe that he'll soon let go of the rope in order to sadistically quash the last glimmer of hope he himself sparked. The general point here is that one can be forced by practical circumstances, especially in dire straits, to trust someone to $\phi$ even when one doesn't believe that that person will $\phi$ or intends to $\phi$.

The point holds for trusting in general and so applies to the context relevant to Fricker's argument, i.e. trusting someone's telling. Suppose you are a foreign spy living in a country whose secret services are bent on discovering, torturing and killing foreign spies. One of your less reliable sources calls you on the phone and says: 'Leave now. The secret services are coming to get you!' Suppose that you are not sure that your source speaks from knowledge, as half of her tips in the past have turned out to be true and half have turned out to be false (though in the latter circumstances it was not her fault - she genuinely believed what she told you). Consequently, you don't believe that she would not easily assert p unless she knew p, though we can stipulate that you believe the weaker counterfactual that she would not easily say p unless she believed (with some reason) that p. You think to yourself 'The consequences of not trusting her word could mean an extremely painful death. So I should trust what she says in this case'. You take her word for it and run.

The point illustrated by this example is that when the stakes are high it is possible - indeed it makes sense - to trust S's telling even if you do not believe the counterfactual: $S$ wouldn't easily tell me that $p$ unless $S$ knew that $p$. Believing weaker counterfactuals that don't invoke knowledge, such as $S$ wouldn't easily tell me that $p$ unless $S$ believed that $p$, or $S$ wouldn't easily tell me that $p$ unless $S$ believed $p$ with good reason can do just as 
well - and in particularly severe circumstances one may be required to trust someone's telling even while nurturing strong doubts about the adequacy of the speaker's epistemic position, and about any counterfactual of the kind we considered. This simple point, however, directly contradicts Fricker's account of trust.

Moreover, just as you might be forced to trust someone whom you don't believe to be trustworthy, you may also choose to trust someone without believing them to be trustworthy. For example, you can (once again!) choose to trust your forgetful friend to return the book they borrowed from you despite harboring strong and justified doubts that they will do so, given ample evidence of their past forgetfulness. There are several reasons why you might do this: perhaps because she has asked you to, and it would put a strain on your friendship if you didn't; or perhaps because your placing trust in her can test how willing she is to overcome her own forgetfulness for your sake, and thereby reveal how thoughtful a friend she is. (And you may say, after the latest disappointment: 'How silly of me! I trusted her yet again despite all the evidence that she would not return the book'.) The same kind of point holds for the context of testimony: a mother can choose to trust her teenage daughter who tells her 'Nobody will be drinking at the party' because only by doing so the mother can bring herself to give her daughter permission to attend. And the mother may very well do this without believing that her daughter knows that nobody will be drinking, in full knowledge that the daughter would tell her the same thing regardless of whether she knew it to be true.

I take these considerations to pose a problem for any conception of trust in terms of belief, and hence, in particular, for Fricker's understanding of trusting a telling as being constituted by the hearer's belief that the speaker 
would not say p unless they knew that p. Fricker's conception of trust does not jibe with the correct understanding of this notion.

In reply, Fricker might concede the point that her notion of trust fails to map onto trust as we naturally understand it, but argue that her intention was to provide an account of a different concept rather than capture what naturally goes by the label 'trust'. Or, she may say, there are a plurality of notions of trust, and she is only interested in the one that her account successfully describes.

The problem with this response is that if the notion of trust that Fricker is working with is not the natural and central one that other theorists are discussing, it's not clear why she takes her notion to correctly account for realworld phenomena, i.e., central and basic cases of testimony through trust. Nor is it clear why she claims that the mechanism that explains knowledge spreading in these cases also explains the same real-world phenomenon in non-paradigmatic cases. ${ }^{18}$ After all, the cases just described seem to be counterexamples to Fricker's preferred account of trusting speakers' testimony. To deny that they intend to trade in the same notion of trust as Fricker risks making futile any debate with Fricker over whether 'testimony via trust' is necessarily second-hand knowledge: Fricker would be analytically and unassailably correct in her views if trusting a telling that $\mathrm{p}$ is defined as believing that the speaker wouldn't easily assert that p unless they knew that p. Of course, defining a theoretical notion is legitimate per se. But if we don't allow this notion to be tested against the real-world subject matter it is used to theorise over, and allow it to be possibly falsified by that subject matter, then we are not really theorising about the subject matter. So the response under consideration is not adequate insofar as Fricker is interested in giving

\footnotetext{
${ }^{18}$ 'This is the distinctive mechanism involved in the spreading of knowledge through trust in telling, and in testimony more broadly' [my italics]. (601)
} 
an account of the genuine phenomenon of trusting speakers' tellings, which is Fricker's explicitly. ${ }^{1920}$

\section{Insufficiency of Argument}

Recall that the overarching aim of Fricker's project is to account for the following datum: in telling $\mathrm{H}$ that $\mathrm{p}, \mathrm{S}$ presents $\mathrm{p}$ as true, or vouches for the truth of p. The explanans of this datum is, for Fricker, that $\mathrm{S}$ purports to speak from knowledge, or represents herself as knowing, ${ }^{21}$ through asserting that p. This occurs allegedly because, by convention, that is what asserting p involves: it involves representing oneself as knowing $\mathrm{p}$, or purporting to speak from knowledge.

As we saw, this is an essential component of Fricker's account of testimonial knowledge through trust as being second-hand knowledge. The idea that in asserting $\mathrm{p}, \mathrm{S}$ purports to speak from knowledge motivates the view that, in hearing S's assertion, $\mathrm{H}$ can form the belief $S$ knows that $p$ and rely on it in the Grounding Argument, which in turn is meant to guarantee that H's knowledge depends on S's prior knowledge.

It's surprising, then, that very little argument is offered for this crucial

\footnotetext{
${ }^{19}$ Along similar lines, one might argue that 'trust' is just a label, and that we could do without this in evaluating Fricker's account. So the failure of Fricker's view of trust to accommodate key cases which the dominant view in the literature on trust is capable of preserving would be irrelevant. On this view, any talk of 'H trusting $\mathrm{S}$ ' is to be reinterpreted as $\mathrm{H}$ believing the counterfactual $S$ wouldn't assert $p$ unless $S$ knew $p$. The worry with this line is that, as the cases above show, belief in this counterfactual does not capture what we think of as trusting someone's testimony. And insofar as this is taken as reason to deem the cases irrelevant, we lose sight of the natural subject matter we are meant to theorise over.

${ }^{20}$ Note that insisting that H's trust must be antecedent to S's telling (see footnote 14) doesn't provide an escape route from the objection raised in this section, since this involves cases where $\mathrm{H}$ trusts the speaker but does not hold the belief which Fricker deems trust-constituting, either before or after the telling. Thanks to an anonymous referee here.

${ }^{21}$ I take 'purporting to know' and 'representing oneself as knowing' to be equivalent in this context, so I will use them interchangeably.
} 
claim. Fricker states simply that the fact that in telling $\mathrm{H}$ that $\mathrm{p}, \mathrm{S}$ represents herself as knowing that $\mathrm{p}$ is a conventionally fixed feature of assertions, of which tellings are a sub-class. ${ }^{22}$ Fricker seems to treat this more as a premise to be relied on than a conclusion to be argued for. In fact, the only data point Fricker mentions is that if $\mathrm{S}$ presents $\mathrm{p}$ as being true, then ' $\mathrm{H}$ can complain to S if p turns out to be false' (594). Admittedly, Fricker's account can accommodate this: one explanation of why $\mathrm{H}$ has grounds for complaint, should $\mathrm{p}$ turn out to be false, is that in telling $\mathrm{H}$ that $\mathrm{p} \mathrm{S}$ purported to know that $\mathrm{p}$, and p's falsehood reveals that S's epistemic status with respect to $\mathrm{p}$ was not what she purported it to be.

Underlying this picture is the thought that liability to H's complaint, if $\mathrm{p}$ is false, demands that what $\mathrm{S}$ purports to do in asserting $\mathrm{p}$ be inconsistent with the falsity of p. In other words, it demands that whatever the speaker purports to do entails the asserted content. Fricker's account satisfies this requirement because in asserting $\mathrm{p}, \mathrm{S}$ purports to know that $\mathrm{p}$, and knowing p entails p. Let's call this requirement the entailment requirement.

There are two points to be made here. The first is that it's not clear that the entailment requirement holds, and if it doesn't, then there are alternative views to Fricker's that can also explain the data point at issue. The second point is that even if the entailment requirement holds, there are alternative views to Fricker's that can also explain it. So either way, Fricker's view is just one among several viable options, and more argument is needed to provide

\footnotetext{
${ }^{22}$ Fricker might reply that she is simply assuming this to be the case. But, while this thesis is a natural companion to the knowledge norm of assertion and a component of the 'knowledge-first' epistemology championed by Williamson (2000) and endorsed by several contemporary philosophers, knowledge-first epistemology and the knowledge norm of assertion are by no means uncontroversial views. So at the very least, Fricker's views would be dialectically effective only for those who share this kind of view. (For arguments in favour of rivals to the knowledge norm, see e.g. Douven (2006) and Lackey (2007). For a recent critical study of 'knowledge-first' epistemology, see McGlynn (2014).)
} 
Fricker's view with an edge over its rivals.

Let's take the points in turn. If the entailment requirement holds, then, for example, the rival proposal on which in asserting that $\mathrm{p} \mathrm{S} \mathrm{purports} \mathrm{to}$ justifiably believe $\mathrm{p}$ will be unable to accommodate the data point that $\mathrm{H}$ can legitimately complain to $\mathrm{S}$ if what she asserted turns out to be false. After all, justified belief is a non-factive notion. ${ }^{23}$ And - so the train of thought runs - if $\mathrm{H}$ were to complain to $\mathrm{S}$ that what she asserted was false, then $\mathrm{S}$ can legitimately deflect the criticism by replying 'But I never meant to say I knew p; only that I justifiably believed p'. This tells against the view that in asserting that $\mathrm{p}, \mathrm{S}$ purports to justifiably believe that $\mathrm{p}$, because H's complaint can always be easily deflected, whereas the data point is that this complaint is legitimate.

But this argument is too quick. It assumes that deflecting the criticism is equivalent to stripping it of its legitimacy. The following, however, may very well be the case: the legitimacy of H's grounds for complaint is grounded only in the fact that $\mathrm{H}$ accepted S's word that $\mathrm{p}$, thereby believed and acted on $\mathrm{p}$, and thereby - given H's later discovery of p's falsehood - made H vulnerable to incurring some practical cost. And this can be the case even if what $\mathrm{S}$ purported to do is consistent with p's falsehood. The legitimacy of H's grounds for complaint are grounded pragmatically.

For example, suppose you justifiably believe but don't know that Gilda passed her exam, and I believe you when you tell me she passed. As it turns out, Gilda failed her exam. Unaware of this, I call her up to congratulate her, and I am now in the middle of an embarrassing conversation. Or I bake a celebratory cake, only to later discover that my time was wasted. It

\footnotetext{
${ }^{23} \mathrm{I}$ am assuming this fallibilist view of justification for the purposes of this argument. Those who disagree can point to an alternative proposal to Fricker's which also satisfies the entailment requirement, as we will see.
} 
seems that I have good reason to complain to you even if in asserting that Gilda passed her exam you purported merely to justifiably believe, and not to know, this. My grounds for complaint are simply that you were the cause of my false belief, a belief that led me to do things I wouldn't have wanted to do if I hadn't held it.

How far does this story generalize? For example, what if I hadn't had time to call Gilda or bake her a cake? If so, your assertion would not have borne a direct practical cost to me; yet it seems I can still complain to you when I discover that Gilda failed her exam.

One way to accommodate the point is to claim that I can complain regardless of whether in fact a practical cost is incurred simply because, in believing a falsehood, I was made vulnerable to incurring some practical cost. This shows that there would be at least one rival to Fricker's view that could accommodate the data point she uses to motivate her knowledge-based account.

However, my general point argument doesn't rest on the success of this maneuver. While practical concerns could explain the legitimacy of H's complaint to $\mathrm{S}$ independently of the entailment requirement, there is further reason to think that there are viable alternative views to Fricker's. The relevant point here is that there are epistemic conditions weaker than knowledge that can express what S purports to do in asserting that $\mathrm{p}$ and that comply with the entailment requirement. For example, one could claim that, in asserting $\mathrm{p}, \mathrm{S}$ purports to truly believe that $\mathrm{p}$. This account complies with the entailment requirement because true belief, unlike justified belief, is factive. Consequently, $\mathrm{H}$ could not deflect criticism from $\mathrm{S}$ after asserting what turns out to be false by saying 'But I never meant to say that $\mathrm{p}$ was true'. This account can explain how, in asserting falsehoods, one makes oneself open to 
reproach and does not require its endorsers to contravene the entailment requirement. It seems no less plausible, at least prima facie, than Fricker's own account. The same can be said of yet another rival view: in asserting that $p$, one purports to justifiably and truly believe (but not necessarily know) that p.

The heart of the matter is that, whether the entailment requirement holds or not, there are a range of alternative views to Fricker's that seek to explain S's vouching for the truth of $\mathrm{p}$ by appealing to weaker epistemic notions than knowledge. By overlooking this kind of option, Fricker is neglecting an important region of logical space.

But even granting this argumentative leap, is there a privileged route from Fricker's thesis - that when $\mathrm{S}$ tells $\mathrm{H}$ that $\mathrm{p}$ she purports to know that $\mathrm{p}$ - to the view that a trusting hearer $\mathrm{H}$ therefore relies on $S$ knows that $p$ as an essential premise in the argument that justifies H's belief that $\mathrm{p}$ ?

The answer is no. Even granting that $\mathrm{H}$ unfailingly believes the desired content that $S$ knows that $p$ whenever $\mathrm{S}$ tells $\mathrm{H}$ that $\mathrm{p}$, there is still no guarantee that that particular belief will play the role Fricker's account requires of it in the architecture of H's justification for p. In other words, what ensures that the hearer's belief that $S$ knows that $p$ will be essentially relied upon in any argument grounding the hearer's belief that p? Fricker provides no argument for this view. But argument is needed, especially since other beliefs may very well play an essential justifying role instead. Recall the Grounding Argument which Fricker proposes as licensing H's belief that p:

\section{The Grounding Argument}

1. $\mathrm{S}$ told me that $\mathrm{p}$ [perception]

2. $\mathrm{S}$ would not easily tell me that $\mathrm{p}$ unless $\mathrm{S}$ knew that $\mathrm{p}$ (Trustworthiness) 
3. $\mathrm{S}$ knows that $\mathrm{p}[1,2]$

4. If $\mathrm{S}$ knows that $\mathrm{p}$, then $\mathrm{p}$ (Factivity) [a priori]

5. $\mathrm{p}[3,4]$

The question is why premise 3 should be an essential part of H's grounds for $\mathrm{p}$, when other premises that do not invoke knowledge are available. For instance, why could the following alternative argument not ground H's belief that $\mathrm{p}$ ?

The Alternative Argument

1. $\mathrm{S}$ told me that $\mathrm{p}$ [perception]

2. $\mathrm{S}$ would not easily tell me that $\mathrm{p}$ unless $\mathrm{S}$ justifiably believed that $\mathrm{p}$ [experience or a priori]

3. S justifiably believes that $\mathrm{p}[1,2]$

4. If $\mathrm{S}$ justifiably believes that $\mathrm{p}$, then $\mathrm{p}$ [experience or a priori]

5. $\mathrm{p}[3,4]$

The Alternative Argument offers a different explanation of how $\mathrm{H}$ gains license to believe $\mathrm{p}$ on S's telling that does not invoke S's knowledge at any stage, and it is not obviously worse-off than Fricker's Grounding Argument. Fricker, however, does not even consider this kind of argument, or any other possible alternative, before drawing the conclusion that the Grounding Argument is what gives $\mathrm{H}$ license to believe that $\mathrm{p}$. In proceeding to this conclusion without argument, Fricker is committing a further, unwarranted argumentative leap. Note again that this leap is significant, because it is crucial to Fricker's argument in favour of SHTK that the belief that $S$ knows 
that $p$ be an essential premise in the argument that sustains H's belief that $\mathrm{p}$ : if H's belief that $\mathrm{p}$ were sustained by an argument that did not contain that $S$ knows that $p$ as an essential premise, then Fricker's case for SHTK would lose its force.

\section{Conclusion}

Fricker's original and rich account of testimony seeks to explain how a hearer is justified in believing the content of a trusted speaker's telling; it is a consequence of this account that testimonial knowledge gained through trust is necessarily second-hand knowledge. I have argued that Fricker's account suffers from several problems. Firstly, in dismissing the key challenge case to SHTK, Fricker significantly misunderstands it; secondly, Fricker's conception of trust is at odds with the desirable distinction between testimonial knowledge gained via trust and testimonial knowledge gained otherwise; thirdly, there is good reason to believe that Fricker's conception of trust fails to capture the real-world phenomena relevant to Fricker's project; fourthly, the proposed architecture of H's justification is undermotivated. On the basis of the cumulative case consisting of these objections, it is reasonable to conclude that Fricker fails to provide a persuasive account of SHTK, and that views that deny SHTK are consequently still very much on the table. ${ }^{24}$

\footnotetext{
${ }^{24}$ For helpful discussion on the themes of this paper, I am grateful to Tim Button, Branden Fitelson, Lauren Garrett, Peter Hartl, Giacomo Melis, Ulrich Stegmann, Paula Sweeney, Stephan Torre, Matthew Townsend, Elia Zardini, and to participants of the Knowledge from Non-Knowledge Symposium at the University of Cambridge and of the Basic Knowledge Workshop X at Northern Institute of Philosophy, University of Aberdeen.
} 


\section{References}

Audi, R. (1997). The place of testimony in the fabric of knowledge and justification. American Philosophical Quarterly, 34, 405-422.

Audi, R. (2006). Testimony, credulity, and veracity. In J. Lackey \& E. Sosa (Eds.), The epistemology of testimony (p. 25-49). Oxford: Oxford University Press.

Audi, R. (2007). Justifying grounds, justified beliefs and rational acceptance. In G. J. Timmons M. \& A. Mele (Eds.), Rationality and the good (p. 222-247). Oxford: Oxford University Press.

Baier, A. (1986). Trust and antitrust. Ethics, 96, 231-260.

Baier, A. (1992). Tanner lectures on human value (Vol. 13). Salt Lake City: University of Utah Press.

Burge, T. (1993). Content preservation. Philosophical Review, 102, 457-488.

Carter, J. A., \& Nickel, P. (2014). On testimony and transmission. Episteme, $11(2), 145-155$.

Douven, I. (2006). Assertion, knowledge, and rational credibility. Philosophical Review, 115, 449-485.

Faulkner, P. (2007). On telling and trusting. Mind, 116, 875-902.

Fricker, E. (1987). The epistemology of testimony. Aristotelian Society Supplementary Volume, 61, 57-83.

Fricker, E. (1994). Against gullibility. In K. Matilal \& A. Chakrabarti (Eds.), Knowing from words (p. 125-161). Dordrecht: Kluwer.

Fricker, E. (1995). Telling and trusting: Reductionism and anti-reductionism in the epistemology of testimony. Mind, 104, 393-411.

Fricker, E. (2002). Trusting others in the sciences: A priori or empirical warrant? Studies in the History and Philosophy of Science, 33, 373383. 
Fricker, E. (2004). Testimony: Knowing through being told. In S. M. Niiniluoto I. \& J. Wolenski (Eds.), Handbook of epistemology (p. 109-130). Dordrecht: Kluwer.

Fricker, E. (2006a). Second-hand knowledge. Philosophy and Phenomenological Research, 73, 592-618.

Fricker, E. (2006b). Testimony and epistemic autonomy. In The epistemology of testimony (p. 225-250). Oxford: Oxford University Press.

Graham, P. (2006). Can testimony generate knowledge? Philosophica, 78 , 105-127.

Hawley, K. (2014). Trust, distrust and commitment. Noûs, 48, 1-20.

Hieronymi, P. (2008). The reasons of trust. Australasian Journal of Philosophy, 86, 213-236.

Hinchman, E. S. (2005). Telling as inviting to trust. Philosophy and Phenomenological Research, $70(3)$, 562-587.

Holton, R. (1994). Deciding to trust, coming to believe. Australasian Journal of Philosophy, 72, 63-76.

Jones, K. (1996). Trust as an affective attitude. Ethics, 107, 4-25.

Lackey, J. (1999). Testimonial knowledge and transmission. Philosophical Quarterly, 49, 471-490.

Lackey, J. (2007). Norms of assertion. Nô̂s, 41, 594-626.

Lackey, J. (2008). Learning from words: Testimony as a source of knowledge. Oxford: Oxford University Press.

Malmgren, A. (2006). Is there a priori knowledge by testimony? Philosophical Review(115), 199-241.

Malmgren, A. (2014). A priori testimony revisited. In A. Casullo \& J. Thurow (Eds.), The a priori in philosophy. Oxford: Oxford University Press.

McDowell, J. (1994). Knowledge by hearsay. In A. Charkrabarti \& K. Matilal 
(Eds.), Knowing from words (p. 195-224). Dordrecht: Kluwer.

McGeer, V. (2008). Trust, hope and empowerment. Australasian Journal of Philosophy, 86, 237-254.

McGlynn, A. (2014). Knowledge first? Palgrave McMillian.

Reynolds, S. (2002). Testimony, knowledge and epistemic goals. Philosophical Studies, 110, 139-161.

Ross, J. (1975). Testimonial evidence. In Analysis and metaphysics: Essays in honor of R.M. Chisholm. Dordrecht: Reidel.

Welbourne, M. (1994). Testimony, knowledge and belief. In A. Charkrabarti \& K. Matilal (Eds.), Knowing from words. Dordrecht: Kluwer.

Williamson, T. (2000). Knowledge and its limits. Oxford: Oxford University Press. 